\title{
Differentiation of Diastereoisomers of Protected 1,2-Diaminoalkylphosphonic Acids by El Mass Spectrometry and Density Functional Theory
}

\author{
Ewelina Drabik, ${ }^{1}$ Grzegorz Krasiński, ${ }^{2}$ Marek Cypryk, ${ }^{2}$ Roman Błaszczyk, ${ }^{3}$ \\ Tadeusz Gajda, ${ }^{3}$ Marek Sochacki ${ }^{*}, 1$
}

${ }^{1}$ Centre of Molecular and Macromolecular Studies, Polish Academy of Sciences, Laboratory for Analysis of Organic Compounds and Polymers, Łódź, Poland

${ }^{2}$ Centre of Molecular and Macromolecular Studies, Polish Academy of Sciences, Department of Computer Modeling, Łódź, Poland

${ }^{3}$ Lodz University of Technology, Institute of Organic Chemistry, Łódź, Poland

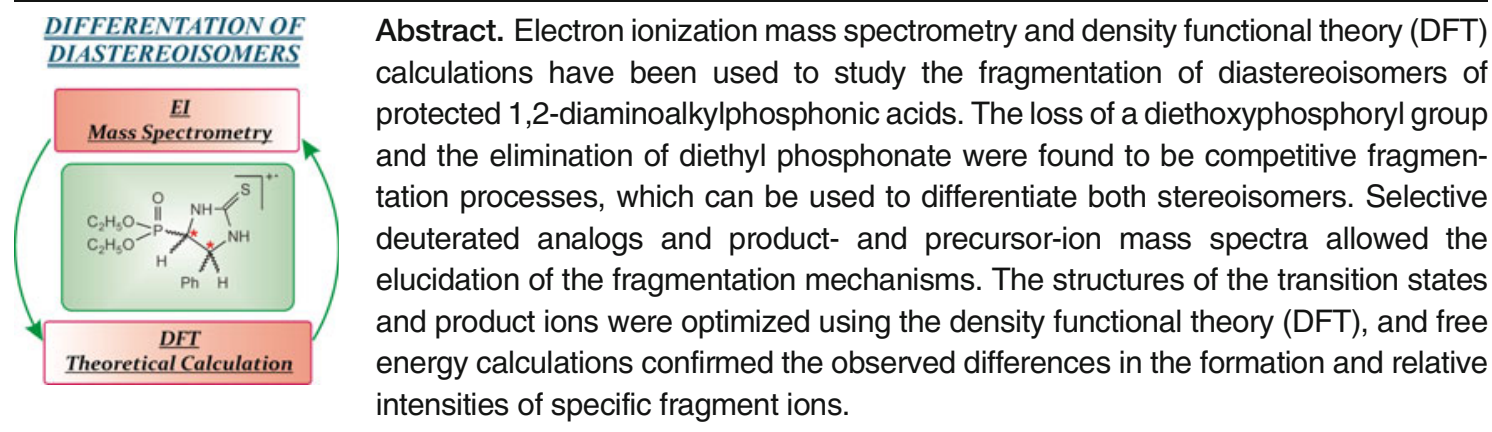

Key words: Aminoalkylphosphonic acids, Electron ionization, Differentiation of diastereoisomers, Fragmentation mechanism, Density functional theory, Collision induced dissociation

Received: 22 June 2012/Revised: 28 November 2012/Accepted: 29 November 2012/Published online: 8 February 2013

\section{Introduction}

$\mathrm{T}$ he synthesis and quantitation of enantiomerically and/or diasteromerically pure compounds is important for a wide range of applications. Chirally pure compounds are not only required in pharmacology, but they are also of interest in the cosmetic and food industries, among numerous other applications. The differentiation of diastereoisomers due to their different physicochemical properties can be achieved in several ways. In many cases, chromatographic methods allow the separation of diastereomeric species, and each of them can be further characterized using appropriate physicochemical or spectral methods. Mixtures of diastereoisomers can be analyzed without the need for separation with some spectral methods (e.g., nuclear magnetic resonance [NMR]). Mass spectrometry alone can be used to characterize separated, pure diaster-

\footnotetext{
*We are saddened for the loss of Marek Sochacki who passed away unexpectedly on August 9, 2012.
}

Electronic supplementary material The online version of this article (doi:10.1007/s13361-012-0556-y) contains supplementary material, which is available to authorized users.

Correspondence to: Ewelina Drabik; e-mail: ewdrabik@wp.pl eoisomers or as a hyphenated technique with gas chromatography or high-pressure liquid chromatography for the analyses of mixtures of diastereoisomers. For many years, mass spectrometry has played an important role in the differentiation of diastereoisomers irrespective of the ionization technique used $[1,2]$. Paradoxically, "hard" ionization techniques (electron ionization [EI], liquid secondary ion mass spectrometry [LSIMS], or fast atom bombardment [FAB]) can provide more informative spectra of diastereoisomers, even when simple mass spectrometers (single focusing) are used, compared with "soft" ionization techniques (chemical ionization [CI], electrospray [ESI] or matrix-assisted laser desorption/ionization [MALDI]), which require instruments with a collision cell to fragment the stable protonated or cationized molecules produced during the ionization process. Mass spectrometry coupled with the quantum chemistry methods (QM) constitutes a promising and valuable scientific tool for interpretation of the experimental spectra. The use of both approaches is beneficial for understanding the mechanisms of MS-type fragmentations and for assigning the correct structures to $\mathrm{m} / \mathrm{z}$ peaks.

Aminoalkylphosphonates and hydroxyalkylphosphonates, which are analogues of amino acids and hydroxyacids, 
respectively, have attracted the attention of bioorganic chemists because of their antiviral and antibiotic properties and their inhibitive activity towards several enzymes [3-7]. Difunctionalized alkylphosphonates (e.g., 1,2-diaminoalkylphosphonates and 1-hydroxy-2-aminoalkylphosphonates) also possess biological activity, and methods for their synthesis have been published [8]. Because of the presence of two stereogenic carbon atoms, these compounds form a diastereoisomeric mixture that can be separated into the individual stereoisomers. Recently, we found that the diastereoisomers of diethyl 5 -substituted ( $N$-1-t-butoxycarbonyl-2-thioxoimidazolidine-4-yl)phosphonates can be easily differentiated using electron ionization mass spectrometry [9].

In the present paper, we report density functional theory calculations for the fragmentation processes responsible for the differentiation of the diastereoisomers of diethyl 5phenyl-2-thioxoimidazolidine-4-yl)phosphonates (Scheme 1).

\section{Experimental}

\section{Synthesis of the Compounds}

Compounds 1-8 were obtained from diethyl $N$-Boc 5substituted (2-thioxo-imidazolidin-4-yl)phosphonates by deprotecting the Boc group using $50 \%$ trifluoroacetic acid (TFA) in dichloromethane (DCM) according to the pub-

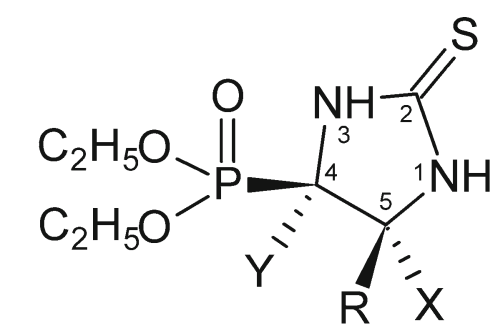

$\begin{array}{llll}\text { cis-1 } & \mathrm{R}=\mathrm{Ph} & \mathrm{X}=\mathrm{H} & \mathrm{Y}=\mathrm{H} \\ \text { cis-3 } & \mathrm{R}=\mathrm{Ph} & \mathrm{X}=\mathrm{D} & \mathrm{Y}=\mathrm{H} \\ \text { cis-5 } & \mathrm{R}=\mathrm{Ph}-\mathrm{d}_{5} & \mathrm{X}=\mathrm{H} & \mathrm{Y}=\mathrm{H} \\ \text { cis-7 } & \mathrm{R}=\mathrm{Ph} & \mathrm{X}=\mathrm{H} & \mathrm{Y}=\mathrm{D}\end{array}$

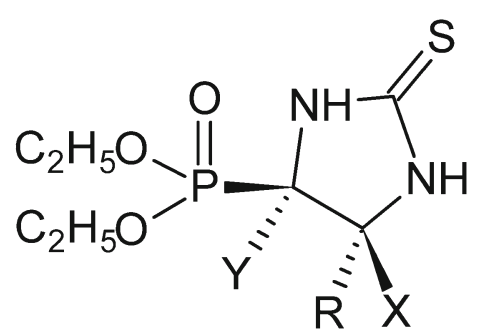

$\begin{array}{llll}\text { trans-2 } & \mathrm{R}=\mathrm{Ph} & \mathrm{X}=\mathrm{H} & \mathrm{Y}=\mathrm{H} \\ \text { trans-4 } & \mathrm{R}=\mathrm{Ph} & \mathrm{X}=\mathrm{D} & \mathrm{Y}=\mathrm{H} \\ \text { trans-6 } & \mathrm{R}=\mathrm{Ph}-\mathrm{d}_{5} & \mathrm{X}=\mathrm{H} & \mathrm{Y}=\mathrm{H} \\ \text { trans-8 } & \mathrm{R}=\mathrm{Ph} & \mathrm{X}=\mathrm{H} & \mathrm{Y}=\mathrm{D}\end{array}$

Scheme 1. Molecular structures of Compounds 1-8 lished procedure [10]. The homogeneity of the samples after deprotection was verified by TLC analysis.

The procedure for the synthesis of $N$-Boc 5 -substituted (2-thioxo-imidazolidin-4-yl)phosphonates has been described in the literature [11]. The isotopically labeled $N$ Boc 5-substituted (2-thioxo-imidazolidin-4-yl)phosphonates were obtained as described [9] using benzaldehyde $-\alpha-\mathrm{d}_{1}$ 98 \% D (Sigma-Aldrich Chemie, Steinheim, Germany) and benzaldehyde-2,3,4,5,6- $\mathrm{d}_{5} 99.7 \%$ D (Dr. Ehrenstorfer, Augsburg, Germany), respectively, as substrates. In the case of $N$-Boc (4-deuterio-5-phenyl-2-thioxoimidazolidin-4yl)phosphonates 7_a and 8_a, paraformaldehyde- $\mathrm{d}_{2} 98 \%$ D (Sigma-Aldrich) was used as the starting material in the first step of the synthesis. A detailed description of the procedure for the synthesis of Compounds $\mathbf{7} \_\mathbf{a}$ and $\mathbf{8} \_\mathbf{a}$ is included in the Supporting Information.

The diastereoisomeric mixtures of Compounds 7_a and 8_a were resolved into individual cis- and trans-diastereoisomers using preparative TLC (Analtech UV254 plates, Bruchsal, Germany). The homogeneity of the samples was subsequently confirmed using TLC analysis and ${ }^{31} \mathrm{P}$ and ${ }^{1} \mathrm{H}$ NMR spectroscopy (see Supporting Information).

\section{Mass Spectrometry}

All mass spectra were recorded on a Finnigan MAT 95 double focusing (BE geometry) mass spectrometer (Finnigan MAT, Bremen, Germany). Standard low-resolution EI mass spectra were obtained using electron energy of $70 \mathrm{eV}$, accelerating voltage of $4.6 \mathrm{kV}$, and ion source temperature of $250{ }^{\circ} \mathrm{C}$. Samples were introduced via a direct insertion probe heated from 30 to $300{ }^{\circ} \mathrm{C}$. Accurate mass measurements were performed by a peak matching technique using perfluorokerosene as an internal standard at a resolving power of 10,000 (10\% valley definition). The product ion, precursor ion, and neutral-loss spectra in the first field-free region (between the ion source and the magnetic sector) were recorded using the appropriate linked scan function: $B /$ $E=$ constant, $B^{2} / E=$ constant and $B^{2} / E^{2}\left(E_{0}-E\right)=$ constant, respectively. For collision-induced dissociation (CID) experiments, argon was used as a collision gas at a pressure appropriate to reduce the intensity of the precursor or product ions by half.

\section{Computational Methods}

Computations were performed using the Gaussian 03 software package [12]. The hybrid functional form B3LYP, which consists of Becke's three-parameter exchange functional [13], and Lee et al.'s correlation functional [14], combined with the $6-31 \mathrm{G}^{*}$ basis set [15], proved to be one of the most accurate and successful methods for reproducing the molecular structures and properties. Moreover, this method requires significantly less computing time than other methods that show similar accuracy. Because our studies involve radical species, all of the structures were optimized 
using the unrestricted B3LYP/6-31G* level of approximation. Harmonic frequency analysis was performed at the same level to characterize and confirm all stationary points to be either local energy minima (represented by no imaginary frequencies) for substrates, products and intermediates, or first-order saddle points (represented by one imaginary frequency) for transition states. Transition states were verified by the IRC calculations to connect the proper, respective minimum structures along the decomposition pathways. Thermal corrections to the enthalpy and entropy were included for the temperature $298.15 \mathrm{~K}$. Because the chemical transformations under study involve radical ions, we used the more advanced triple-zeta basis set, denoted as $6-311+G(2 d, p)$, augmented with the diffusion functions and with additional polarization functions to obtain more reliable energies [16]. All calculations were performed with no symmetry restrictions for the gas-phase conditions.

We tested the reliability of our method against the more advanced and time-consuming method M06-2x/6-311+G(2d, p) [17] and recalculated the final single point energies at the M06-2X/6-311+G(2d,p)//B3LYP/6-31G(d) level. Based on the obtained results, we concluded that the energetics of the reactions are not significantly affected when the functional is changed from B3LYP to M06-2x. The energy barriers calculated using the M06-2X method are systematically greater (by $4-5 \mathrm{kcal} / \mathrm{mol}$ ) than those calculated using B3LYP. The results are presented in the Supporting Information (Table S1). The order of feasibility of the various fragmentation pathways remained unchanged, and the conclusions of the work based on the B3LYP calculations are valid. Because the M06-2X method is more computationally expensive, we did not perform optimizations at this level of theory. Natural bond orbital analysis (NBO) was performed to calculate atomic charges and spin densities [18]. The optimized structures and atomic charges were visualized using the GaussView 4.1 software package [19].

\section{Results and Discussion}

The electron ionization mass spectra of Compounds 1-8 are summarized in Table 1. All the investigated compounds are characterized by a molecular ion and a few prominent fragment ions. The relative abundance of the molecular ion is significantly higher for the cis isomer in each analyzed pair of diastereoisomers and varies from $75 \%$ to $100 \%$. For the trans isomers, the relative abundance ranges from $10 \%$ to $36 \%$. In addition, the molecular ion abundances in the total ion current ( $\%$ of TIC) differ significantly for all the cis- and trans pairs of diastereoisomers, being $6.4 \%-8.4 \%$ for the cis- and $1.9 \%-3.8 \%$ for the trans isomers, respectively. These results indicate the difference in the stability of the molecular ion, which is lower for the cis isomer in each analyzed pair. Thus, the fragmentation of cis isomers leads to more ions of lower absolute abundance, whereas the trans isomers give rise to a few ions of higher abundance.

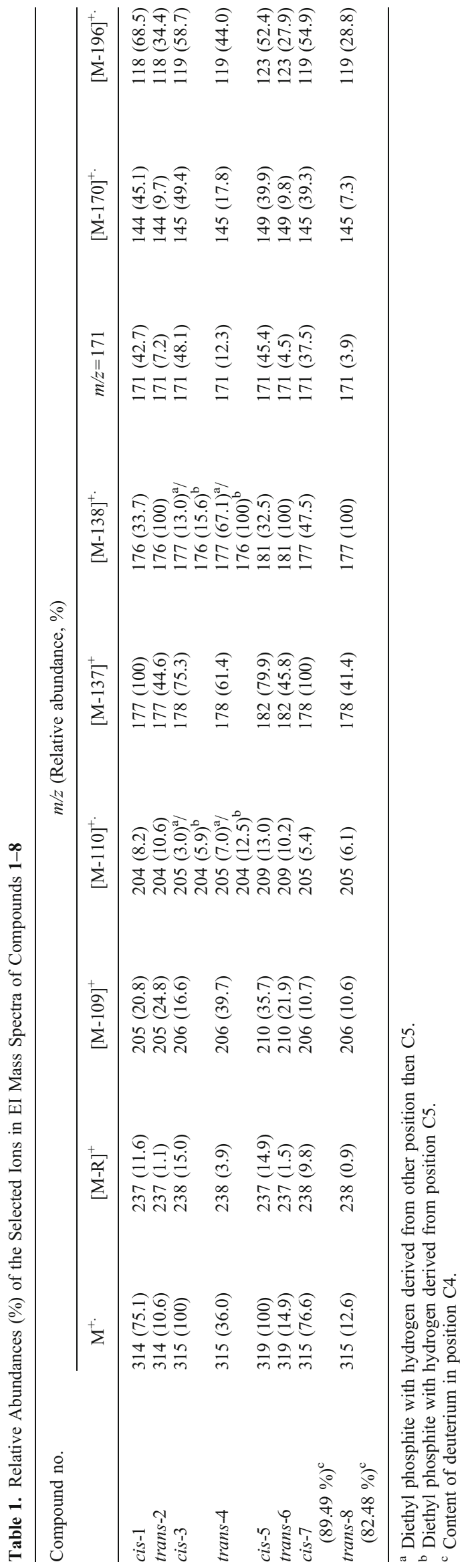


The conformer analyses of molecular ions of cis-1 and trans-2 were performed (Figures S3 and S4 and Table S2, Supporting Information). Because of the size and flexibility of the molecules, numerous different conformers were distinguished; however, only one (described below) was found to be the global minimum on the free energy surface (Figure 1). In these structures, specific intramolecular interactions, such as hydrogen bonds formed by all oxygen atoms of the phosphonate moiety, are present. H-bonds of type $\mathrm{P}=\mathrm{O}-\mathrm{H}-\mathrm{N}$ and $\mathrm{C} 5_{\text {ring }}-\mathrm{H}_{\mathrm{d}}-\mathrm{O}_{\mathrm{Et}} \mathrm{P}$ can be localized in both diastereoisomers $(2.643 \AA$ and $2.792 \AA$ for cis-1 and $2.479 \AA$ and $2.466 \AA$ for trans-2). The third short-distance interaction is $\mathrm{C}_{\text {ring }}-\mathrm{H}_{\mathrm{c}}-\mathrm{O}_{\mathrm{Et}} \mathrm{P}$ (2.613 $\AA$ in length) for trans2 and $\mathrm{C}_{\mathrm{Ph}}-\mathrm{H}-\mathrm{O}_{\mathrm{Et}}-\mathrm{P}(2.484 \AA)$ in the case of isomer cis-1.

A comparison of the Gibbs free energy for both diastereoisomers indicates that the trans form is more stable due to additional intramolecular interactions and less steric hindrance of the bulky groups: $\mathrm{Ph}$ and $(\mathrm{EtO})_{2} \mathrm{P}=\mathrm{O}$ are placed on the opposite side of the imidazolidine ring. The difference is equal to $5.9 \mathrm{kcal} / \mathrm{mol}$. These data are consistent with the experimental observation that fragmentation of the cis isomers gives rise to a greater number of fragmentation ions than fragmentation of the trans isomers.

Based on the Mulliken and the Natural Population analyses, we determined the electron spin density of both structures of interest and defined the location of the singly occupied molecular orbital (SOMO). According to these calculations, the SOMO orbital is mostly concentrated on the sulfur thiono-atom (Table S3, Supporting Information). The neutral molecules of both diastereoisomers (uncharged, singlet state) undergo numerous significant structural changes after losing an electron, and these structural changes occur primarily in the region of unpaired electron localization. The deeper consideration of the change of structural parameters of SUB_cis_1 and SUB_trans_2 confirms that the main changes emerge in the thiono part N3-C2(=S6)-N1 (Table S4, Supporting Information).

Our previous studies have shown that the cis- and transdiastereoisomers of $N$-Boc diethyl 5-substituted (2-thioxoimidazolidin-4-yl) can be easily differentiated based on their EI mass spectra [9]. The most important differences were observed for ions formed by loss or elimination of the diethoxyphosphoryl group. Here, we show that the 5phenylo-(2-thioxo-imidazolidin-4-yl)phosphonates cis-1 and trans-2 and their specific deuterium labeled analogues 38 can also be distinguished based on two competitive fragmentation processes:

(a) loss of the diethoxyphosphoryl radical via cleavage of the $\mathrm{P}-\mathrm{C} 4$ bond, which leads to the formation of the $[\mathrm{M}-$ $137]^{+}$ion, and

(b) elimination of diethyl phosphite (DEPI), which leads to the formation of the $[\mathrm{M}-138]^{+}$ion.

The relative abundances of the $[\mathrm{M}-137]^{+}$and the $[\mathrm{M}-$ $138]^{+}$. ions differ significantly for all pairs of cis- and trans- diastereoisomers (Table 1). Cleavage of the $\mathrm{P}-\mathrm{C} 4$ bond and loss of the diethoxyphosphoryl radical are preferred for the cis isomer. The relative intensity of the $\mathrm{M}-137$ peak, which corresponds to those processes, varies from $75 \%$ to $100 \%$ for the cis isomers, whereas it changes from $45 \%$ to $64 \%$ for the trans isomers. The elimination of diethyl phosphite is preferred for the trans isomers, and the $\mathrm{M}-138$ peak is the base peak in the mass spectra of all trans isomers.

The percentages of both processes in the fragmentation of the molecular ions for Compounds 1-6 are shown in Table 2.

\section{Loss of the Diethoxyphosphoryl Radical Leading to Formation of the $[M-137]^{+}$Ion}

The obtained EI data indicate that the total relative abundance for loss of the diethoxyphosphoryl radical for cis isomers was approximately $75 \%$ in each pair of diastereoisomers. In the case of trans isomers, this fragmentation process occurred at approximately $25 \%$ relative abundance.

The loss of the substituent considered here occurs via one-step bond-breaking that leads directly to the separated products. For cis-1, the most favorable process is the loss of the diethoxyphosphoryl radical, which is caused by the effective stabilization of the positive charge in the thioimidazolidine ring and, moreover, by the suitable localization of the SOMO in $(\mathrm{EtO})_{2} \mathrm{PO}$ on the phosphorus atom. The abstraction of diethoxyphosphoryl radical with the lowest free energy activation, which is $20.8 \mathrm{kcal} / \mathrm{mol}$, proceeds (TS_L_PO_1) and leads to the most stable products (PROD_L_PO_1) of the relative free energy being $17.1 \mathrm{kcal} / \mathrm{mol}$. Other competitive reactions are more endothermic. The removal of the phenyl radical requires substantially more energy and occurs only above $42 \mathrm{kcal} /$ mol (TS_L_Ph_1) (Scheme 2 and Figure 2a). The products that arise are also less favored than those in the case of the loss of the (EtO) $)_{2} \mathrm{PO}$ radical. Separation of the $\mathbf{H}_{\mathbf{c}}$ and $\mathbf{H}_{\mathbf{d}}$ hydrogen atoms differs significantly. The $\mathbf{H}_{\mathbf{c}}$ bound to $\mathrm{C} 5$ dissociates more easily than does $\mathbf{H}_{\mathbf{d}}$ because of the essential stabilization effect of the positive charge on $\mathrm{C} 5$ due to the directly bound phenyl ring (via resonance because both

Table 2. The Processes of Fragmentation with Diethoxyphosphoryl Group for Compounds 1-6 Contributed in Percent (\%)

\begin{tabular}{clc}
\hline Compound No & $\begin{array}{c}\text { Elimination of diethyl } \\
\text { phosphonate }(\%)\end{array}$ & $\begin{array}{c}\text { Dissociation of P-C bond } \\
\text { and loss of radical (\%) }\end{array}$ \\
\hline cis-1 & 26.0 & 74.0 \\
trans-2 & 75.3 & 24.7 \\
cis-3 & $26.8\left(15.7^{\mathrm{a}} ; 11.1^{\mathrm{b}}\right)$ & 73.2 \\
trans-4 & $75.8\left(48.8^{\mathrm{a}} ; 27.0^{\mathrm{b}}\right)$ & 24.2 \\
cis-5 & 29.9 & 70.1 \\
trans-6 & 74.6 & 25.4 \\
\hline
\end{tabular}

a Diethyl phosphite with hydrogen derived from position C5.

b Diethyl phosphite with hydrogen derived from other position than C5. 
(a)

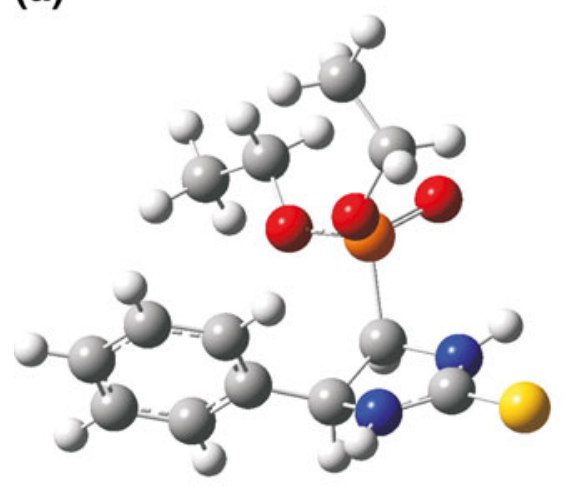

(b)

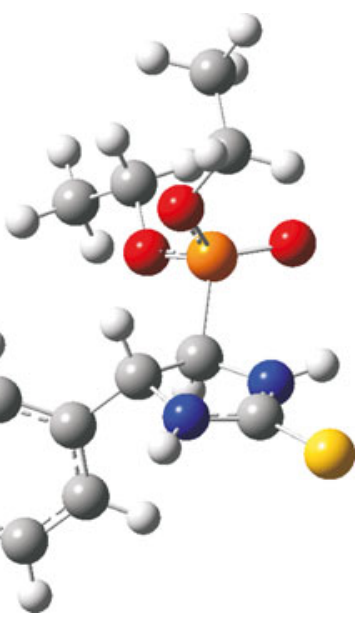

Figure 1. The most stable conformers of molecular ions of (a) the cis-1 (SUB_cis_1) and (b) the trans-2 (SUB_trans_2) isomers

phenyl and thioimidazolidine rings are planar and are located in the same plane). The opposite influence of the $(\mathrm{EtO})_{2} \mathrm{PO}$ group on the positive charge on $\mathrm{C} 4$ can be observed, and the $\mathbf{H}_{\mathbf{d}}$ abstraction is therefore the least likely. The SOMO in the substrate is mainly located on the sulfur atom. NBO population analysis of the evolution of spin densities in the transition state structures reveals that, in all pathways, the essential part of the spin density is transferred from the sulfur atom to the bond-breaking area (Table S5, Supporting Information).

A similar analysis performed for the trans-2 isomer leads to the same conclusions. The loss of the diethoxyphosphoryl

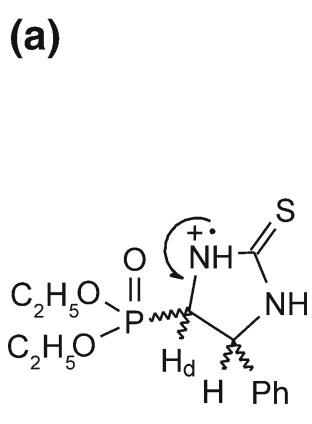

SUB

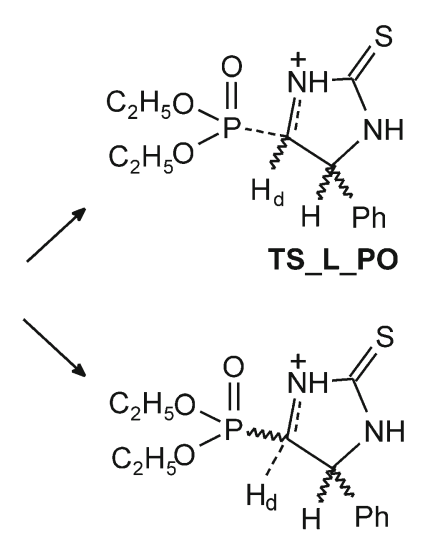

TS_L_H
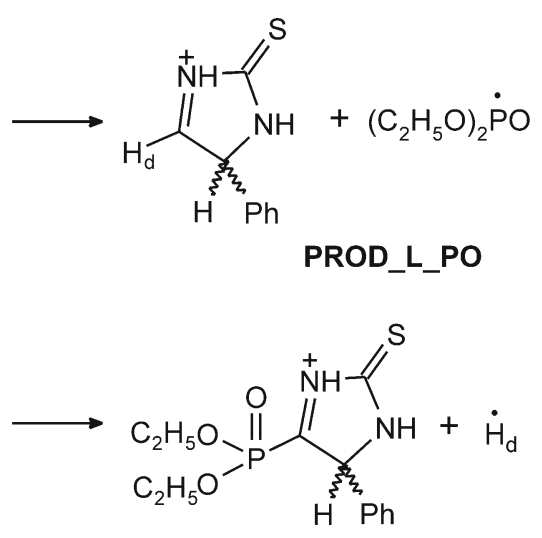

PROD_L_H

(b)<smiles>CCOP(=O)(OCC)[C@H](NC(=S)[NH2+]C(c1ccccc1)c1ccccc1)C1CCCCC1</smiles>

SUB

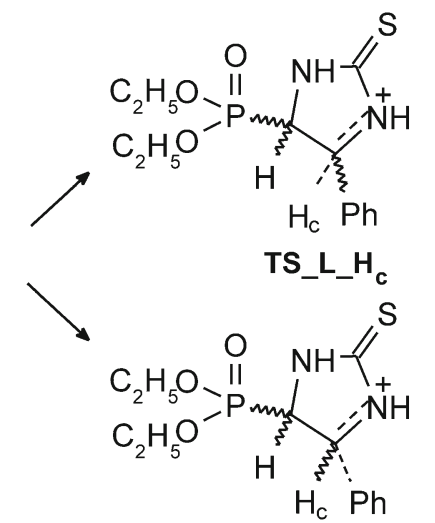

TS_L_Ph<smiles>CC=COP(=O)(OCC)[C@H]1NC(=S)[NH+]=C1c1ccccc1</smiles>

PROD_L_H<smiles>CC=C[C@@H](NC(=S)[NH2+][SnH+]c1ccccc1)P(=O)(O)OCC</smiles>

PROD_L_Ph

Scheme 2. Loss of the substituents from positions (a) C4 and (b) C5 induced by radical sites located on N1 and N3, respectively 
(a)

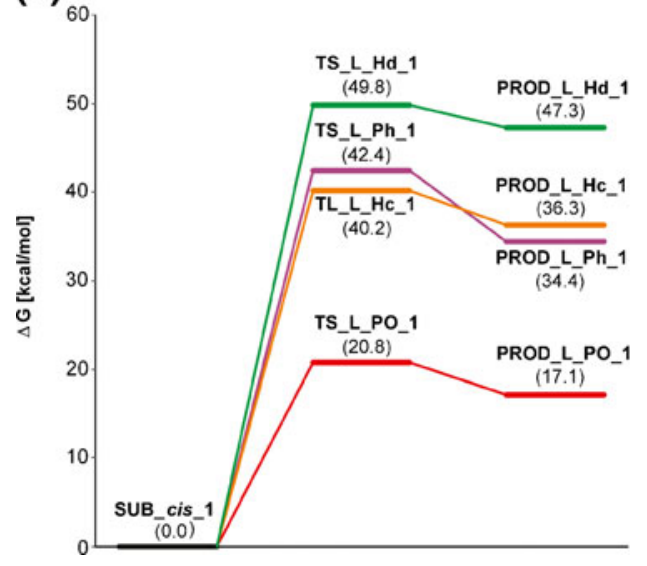

(b)

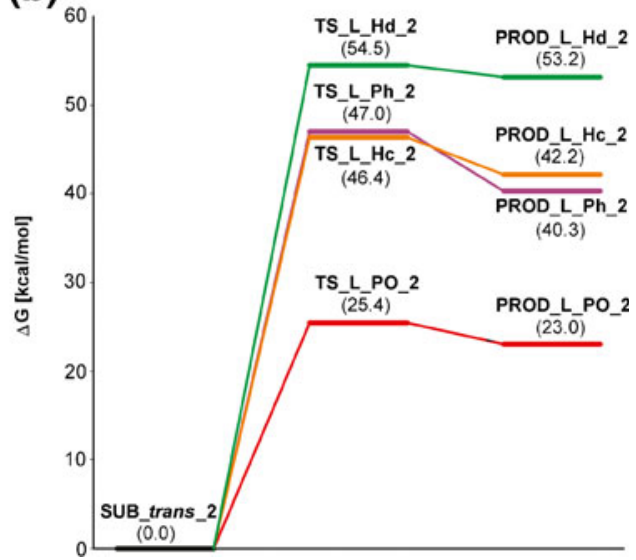

Figure 2. Calculated potential free energy profile for the loss of the substituents from positions C4 and C5 for (a) cis-1 and (b) trans-2 (outlined in Scheme 2)

group from the thioimidazolidine ring is the least energy demanding process. The dependence order of the leaving groups is $(\mathrm{EtO})_{2} \mathrm{PO}>>\mathrm{Ph} \approx \mathrm{H}_{\mathrm{c}}>\mathrm{H}_{\mathrm{d}}$ (Scheme $2 \mathrm{~b}$ ). The most significant observation is that, because of its lower stability, the cis-1 isomer is more likely to undergo fragmentation than is the trans-2 isomer. The reactions of cis-1 are characterized by a lower free energy of activation of approximately $6 \mathrm{kcal} / \mathrm{mol}$ and by a lower energy of the fragmentation. Notably, the products with an imidazolidine ring, after removal of one substituent, lose one stereogenic center; thus, the resulting compounds from cis-1 and trans-2 are enantiomers (from a thermodynamic point of view, they are the same). The obtained results are qualitatively in good agreement with the experimental data when the substituent abstraction from the $\mathrm{C} 4$ and $\mathrm{C} 5$ positions is considered.

\section{Elimination of Diethyl Phosphite (DEPI) Leading to Formation of the $[M-138]^{+}$. Ion}

The diethyl phosphite elimination process requires the migration of a hydrogen atom to the diethoxyphosphoryl group. To determine the source of the hydrogen atom that takes part in the elimination of phosphite, we performed detailed studies of selected deuterium labeled analogues of 5-phenyl-(2-thioxo-imidazolidin-4-yl)phosphonate (Scheme 1).

According to the data obtained previously for the corresponding pairs of diastereoisomers with a tert-butoxycarbonyl group on the N1 nitrogen atom [9], the hydrogen atoms on the atoms adjacent to carbon $\mathrm{C} 4$ (i.e., those on nitrogen N3 or carbon C5) were considered to be the most probable source of the hydrogen atom involved in the elimination of phosphite.

The migration of the hydrogen atom from one of these positions proceeds via a five-membered transition state (Scheme 3a and c). For trans isomers in which a diethoxyphosphoryl group and a hydrogen atom are posi- tioned on the same side of the plane defined by the imidazolidine ring, the migration of the hydrogen occurs more easily than for cis isomers, which can explain the preference for the elimination of diethyl phosphite in the trans isomers.

To examine whether the hydrogen atom from the N3 position can be eliminated, it was exchanged with deuterium in the Compounds cis-1 and trans-2. For both diastereoisomers, we did not succeed in obtaining the fully deuterium-enriched compounds, and the obtained results are therefore ambiguous. For the cis isomer, for which the elimination of DEPI is approximately $25 \%$ total relative abundance, the evaluation of whether the hydrogen atom from the N3 nitrogen is present in the diethyl phosphite molecule is difficult. For the trans isomer, elimination of deuterium from this position occurs at approximately $30 \%$ relative abundance.

To verify the hypothesis that the DEPI elimination involves a hydrogen atom from the C5 position, the cis-3 and trans $\mathbf{4}$ diastereomeric pair with deuterium incorporated into this position were studied. The spectra of these $c i s-$ and trans-diastereoisomers indicate that hydrogen from position C5 participated in the elimination process that led to formation of the DEPI. The percentage of elimination of the diethyl phosphite molecule that contains the deuterium from the $\mathrm{C} 5$ position was calculated, and the results are shown in Table 2. For the cis-3 isomer, elimination of deuterium from the $\mathrm{C} 5$ position occurs at $15.7 \%$ relative abundance, and elimination from the other position occurs at $11.0 \%$ relative abundance. For the trans -4 isomer, elimination of DEPI occurs at $75.8 \%$ relative abundance and consists of the elimination of deuterium from C5 (64.4\%) and hydrogen from other positions (34.6\%), most likely from N3.

In addition, another source of hydrogen atom present in the diethyl phosphite molecule was examined. From the mass spectra of cis-5 and trans-6 pair of diastereoisomers 
(a)

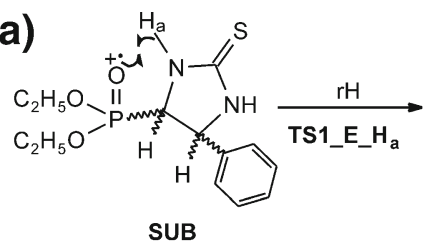

(b)

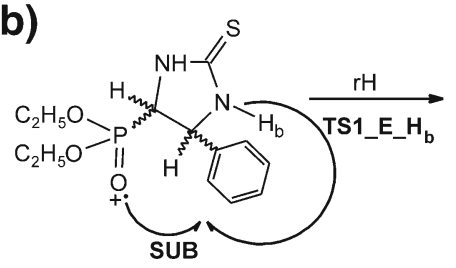

(c)

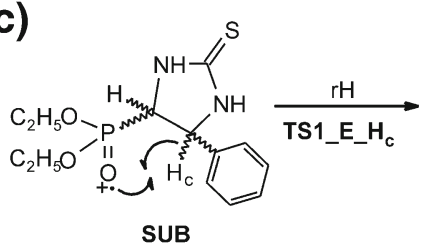

(d)

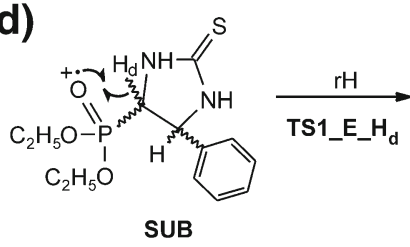

(e)

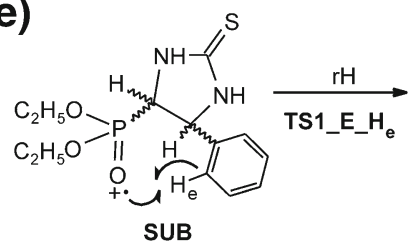<smiles>COP(O)(O)(OC)[C@]1(C)NC(=S)N[C@H]1c1ccccc1</smiles>

INT_E $\mathrm{H}_{\mathbf{a}}$<smiles>Oc1ccccc1C1CNC(=S)NC1c1ccccc1</smiles>

PROD_E_Ha

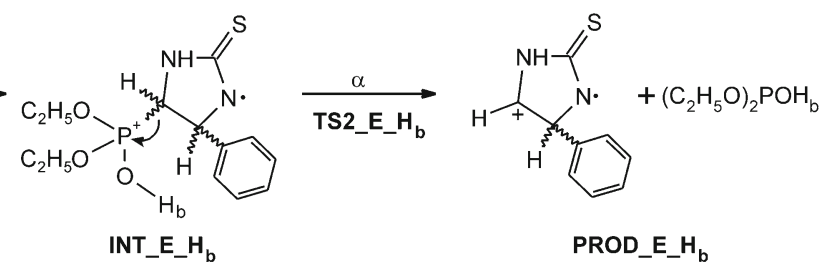

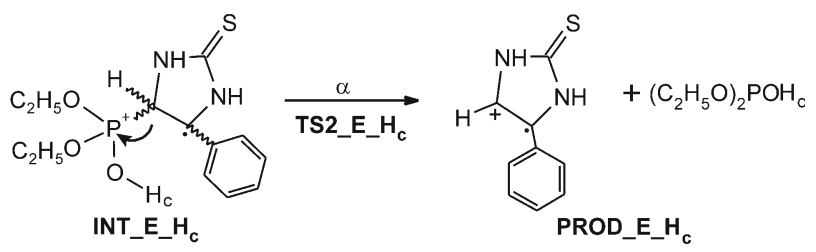

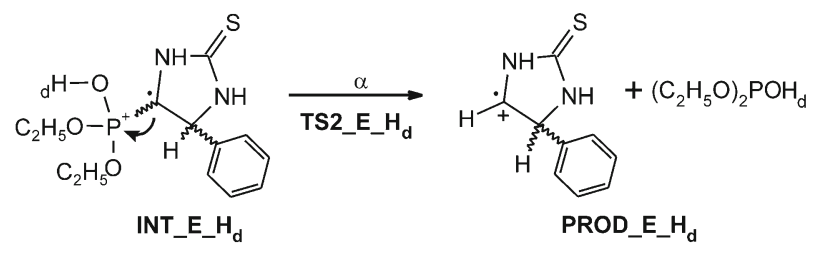

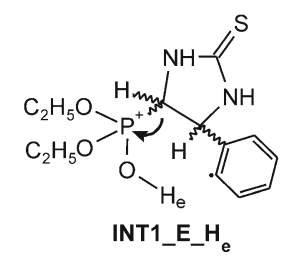

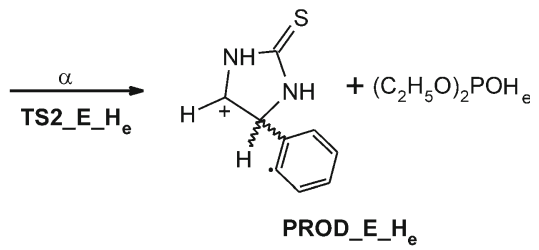

Scheme 3. Possible elimination mechanisms of diethyl phosphite with hydrogen atoms from different positions

that contain $\mathrm{d}_{5}$-labeled phenyl groups, deuterium atoms from the phenyl ring apparently did not participate in the DEP elimination. Similar results were obtained for diastereoisomers cis-7 and trans-8 labeled with deuterium in position $\mathrm{C} 4$. In the course of the synthesis of the cis-7 and trans-8 isomers, the preparation of the fully deuterium labeled compounds was unsuccessful. The cis-7 isomer contained $10.5 \%$ of the parent Compound cis-1, and isomer trans-8 contained approximately $17.5 \%$ of isomer trans-2. The migration of hydrogen from position $\mathrm{C} 4$ proceeds via a three-membered transition state (Scheme 3d). The spectrum of the trans-8 isomer shows that the deuterium atom from this position does not migrate to the phosphoryl group during DEPI elimination for the trans isomer. For the cis-7 isomer, the obtained results are ambiguous, similar to the case of hydrogen from position N3.

Because of the problems encountered in identifying the source of the hydrogen atoms that participate in elimination of the diethyl phosphite molecule and those encountered in evaluating the percentages of particular processes, quantum mechanical DFT calculations were performed; such calculations have been demonstrated to be useful in explaining and predicting the fragmentation patterns of hetero-organic compounds [20,21].

Theoretical DFT calculations allowed to estimate the energies related to the four proposed routes of elimination of the diethyl phosphite, which was studied by electron ionization mass spectrometry using deuterium-labeled compounds. An additional source of hydrogen atom that could participate in the elimination of the DEPI, specifically, that from nitrogen N1, was taken into account. We excluded the phenyl ring and ethoxyl groups as potential donors of hydrogen because both are present in the eliminated fragment. The resulting energy profile for these pathways is shown in Figure 3. The process of DEPI elimination involves two transition states: TS1 and TS2. The first transition state is associated with the intramolecular hydrogen transfer to the diethoxyphosphoryl group, and the other is associated with the dissociation of P-C4 bond (see Scheme 3 and Figure 3). The TS1 and TS2 involve not 

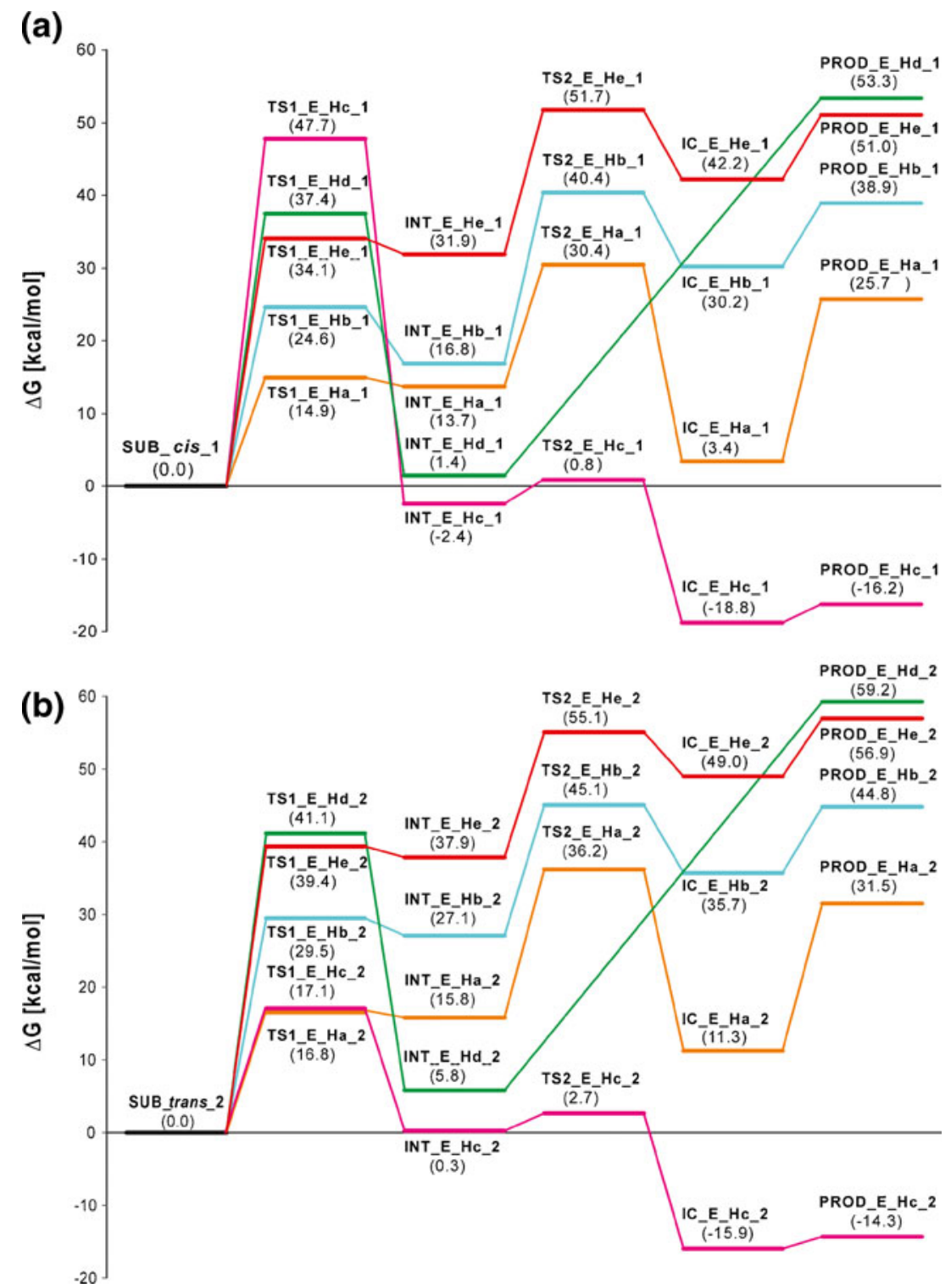

Figure 3. Calculated potential free energy profile for the elimination of diethyl phosphite with hydrogen atoms from different positions for (a) cis-1 and (b) trans-2 (outlined in Scheme 3)

only structural changes, but reorganization of the frontier orbitals, mainly the SOMO. The radical character of the sulfur atom is diminished and relocated to the hydrogen donor in TS1. In TS2, the changes in electron density proceed to flow to the dissociation fragment, mostly to the phosphoryl group and phosphorus atom (Table S6, Supporting Information). The free energy profiles for the diastereoisomers differ. In general, cis-1 requires less energy to overcome barriers (TSs) encountered along the pathway because of its lower stability. For trans-2, the lowest activation barrier for hydrogen migration (TS1) corresponds to TS1_E_ $\mathbf{H}_{\mathbf{a}} \mathbf{2}$ and $\mathbf{T S 1} \mathbf{E}_{-} \mathbf{H}_{\mathbf{c}} \_$; ; its value is approximately $17 \mathrm{kcal} / \mathrm{mol}$, whereas that for $\mathbf{H}_{\mathbf{a}}$ is slightly lower. Among the resulting intermediates, the most stable is that formed when $\mathbf{H}_{\mathbf{c}}$ migrates (INT_E_ $\mathbf{E}_{\mathbf{c} \_}$2). This structure possesses two rings in one plane, which leads to high delocalization of the unpaired electron over the phenyl ring (Table S7, Supporting Information). The dissociation of the $\mathrm{P}-\mathrm{C} 4$ bond in such a structure is facilitated (the energy of TS2 is only $2.5 \mathrm{kcal} / \mathrm{mol}$ greater than that of the intermediate) because TS2 resembles the sum of the products. The products are also highly stabilized because of resonance of positive charge over the phenyl ring. The migration of $\mathbf{H}_{\mathbf{c}}$ and the dissociation of $\mathrm{P}-\mathrm{C} 4$ causes the loss of two stereogenic centers on $\mathrm{C} 4$ and $\mathrm{C} 5$; the products are therefore achiral and the same as in both the cis-1 and trans-2 cases. The energy difference between $\mathbf{T S 1} \mathbf{E}_{-} \mathbf{H}_{\mathbf{a}} \mathbf{2}$ and INT_E_H $\mathbf{H}_{\mathbf{a}} \mathbf{2}$ is only $1.3 \mathrm{kcal} / \mathrm{mol}$, which proves the reversibility of the $\mathbf{H}_{\mathbf{a}}$ migration. The second energy barrier, TS2_E_H $\mathbf{H}_{\mathbf{a}}$ 2, is more than $20 \mathrm{kcal} / \mathrm{mol}$ greater than that of 
INT_E_H $\mathbf{H}_{\mathbf{a}} \mathbf{2}$. The products are significantly less stable than in case of $\mathbf{H}_{\mathbf{c}}$. Another very stable intermediate is INT $\mathbf{E} \mathbf{H}_{\mathbf{d} \_} \mathbf{2}$, whose energy is only $5.8 \mathrm{kcal} / \mathrm{mol}$ higher than that of the substrate. The following $\mathrm{P}-\mathrm{C} 4$ dissociation does not go through TS2 as a consequence of the complex nature of this bond. After the loss of $\mathbf{H}_{\mathbf{d}}$, the $\mathrm{C} 4$ becomes an $\mathrm{sp}^{2}$ carbon atom with one unpaired electron occupying the $\mathrm{p}$ orbital (Table S7, Supporting Information); simultaneously, the $\mathrm{P}-\mathrm{C} 4$ bond becomes shorter and stronger (partly double). As such, significantly more energy is required to break the $\mathrm{P}-\mathrm{C} 4$ bond. Furthermore, the products are high in energy. Other possible $\mathrm{H}$ migrations and $\mathrm{P}-\mathrm{C} 4$ dissociations are characterized by significantly larger free energy barriers (both the TS and the products). The intermediates are structurally and energetically equivalent for both cis-1 and trans-2 because, upon formation of TS1, the molecules lose at least one stereogenic center and become only chiral. The transfer of proton $\mathbf{H}_{\mathbf{c}}$ is better facilitated for the trans-2 isomer than for the cis-1 isomer due to more spatially accessible mutual positions of $\mathbf{H}_{\mathbf{c}}$ and the diethoxyphosphoryl group. Thus, although process c (Figure $3 b$ ) was the leading process for trans-2 (i.e., the process with the lowestenergy TS1, TS2, intermediate and products), it became one of the most energy-demanding processes in the case of cis-2. The reason for this increased energy demand is the proton transfer (i.e., TS1_E_ $\mathbf{E}_{\mathbf{c}} \mathbf{H}_{-} \mathbf{1}$ ), which requires substantial deformation of the structure to occur. The remaining energy profiles for this type of fragmentation are similar for both diastereoisomers.

In our investigations, we have taken into account the possibility that the isomers interchange (mainly cis-1 to trans-2), which could explain the high level of elimination of DEPI with $\mathbf{H}_{\mathbf{c}}$ for the cis isomer. To investigate this phenomenon, we attempted to gain additional insight into the persistence of the ring bonds. In this case, the energies related to homological cleavage of all bonds in the imidazolidine were determined using DFT calculations, and the results are shown in Table 3. Surprisingly, the C4-C5 bond is the weakest one and easily undergoes cleavage (see Table 3). This cleavage can be associated with hydrogen bonds that can stabilize the TS. They are formed between the $\mathbf{H}_{\mathbf{c}}$ and $\mathrm{O}_{9} / \mathrm{O}_{10}(2.297 \AA$ and $2.408 \AA$ in the case of trans-2) and between $\mathbf{H}_{\mathbf{a}}$ and $\mathrm{O}_{8}$ and $\mathbf{H}_{\mathbf{d}}$ and $\mathrm{O}_{9}(2.261 \AA$ and $2.718 \AA$ in the case of cis-1). During C4-C5 cleavage, both cis-1 and trans-2 lose their stereogenic centers (on carbons $\mathrm{C} 4$ and $\mathrm{C} 5$ ), which leads to the same stable products.

Table 3. $\Delta \mathrm{G}$ of the Bond Breakings for cis-1 and trans-2

\begin{tabular}{lrrcrr}
\hline & $\mathrm{C}_{4}-\mathrm{C}_{5}$ & $\mathrm{C}_{4}-\mathrm{N}_{3}$ & $\mathrm{C}_{5}-\mathrm{N}_{1}$ & $\mathrm{~N}_{1}-\mathrm{C}_{2}$ & $\mathrm{~N}_{3}-\mathrm{C}_{2}$ \\
\hline SUB_cis_1 & 0.00 & 0.00 & 0.00 & 0.00 & 0.00 \\
TS & 26.40 & 53.79 & n. d. & 47.25 & 47.13 \\
PRODUCTS & 0.93 & 22.94 & 32.80 & 42.58 & 43.92 \\
SUB_trans_2 & 0.00 & 0.00 & 0.00 & 0.00 & 0.00 \\
TS & 35.96 & 54.83 & n. d. & 47.50 & 50.50 \\
PRODUCTS & 6.81 & 28.83 & 36.69 & 46.47 & 47.81 \\
\hline
\end{tabular}

Successive chemical reactions for such open structures become the same. Moreover, among the diastereoisomers, cis-1 undergoes $\mathrm{C} 4-\mathrm{C} 5$ bond cleavage much more easily than the trans isomer. The energy of the transition structure that leads to the cleavage of the bond between these two carbon atoms in the cis isomer is lower by $9.6 \mathrm{kcal} / \mathrm{mol}$ than that in trans isomer. The free energy barrier for this process, especially for the cis isomer, is comparable to those described previously and can be considered as an introduction to whole family fragmentation patterns. In particular, cleavage of the C4-C5 bond (both carbon atoms involved are stereogenic) and the consequent ring-opening may lead to equilibrium between the cis-1 and trans-2 isomers. After dissociation, a simple change (i.e., rotation) of the N1-C2$\mathrm{N} 3-\mathrm{C} 4$, or N3-C2-N1-C5 dihedral angle followed by the recreation of the $\mathrm{C} 4-\mathrm{C} 5$ bond causes the interconversion of the isomers (isomerization). We have examined this mechanism to explain the presence of the high $176 \mathrm{~m} / \mathrm{z}$ peak for cis-1, for which very unfavorable hydrogen $\mathbf{H}_{\mathbf{c}}$ transfer occurs. The investigation of the energy profile of the hypothetical isomerization process precludes such a possibility. The cleavage of the $\mathrm{C} 4-\mathrm{C} 5$ bond proceeds with an energy barrier of ca. $26 \mathrm{kcal} / \mathrm{mol}$. The barrier for ring closure to give the reversed configuration is greater and is equal to nearly $30 \mathrm{kcal} / \mathrm{mol}$. (The barrier for rotation around N1-C5 is almost $9 \mathrm{kcal} / \mathrm{mol}$ for cis-1 and $14.3 \mathrm{kcal} / \mathrm{mol}$ for trans-1). Thus, this process is more feasible than the direct $\mathbf{H}_{\mathbf{c}}$ transfer in the cis substrate.

\section{Other Fragmentation Pathways}

Other fragmentation pathways for the investigated pairs of diastereoisomers were observed. These processes were detected in standard or production mass spectra and were characteristic mainly of the cis isomer (Figures S1 and S2, Supporting Information). The proposed fragmentation pathways of the cis and trans isomers are shown in Scheme 4.

Among the fragmentation pathways for the cis isomer, except for the loss of substituents from positions $\mathrm{C} 4$ and $\mathrm{C} 5$, the loss of the hydroxyl and ethyl groups as well as the loss of a HNCS molecule were observed. The loss of the hydroxyl radical must proceed by migration of a hydrogen atom to the oxygen of the diethoxyphosphoryl group. The product-ion mass spectra of the molecular ion of the cis-3 isomer show that one of the hydrogen atoms involved in this process of fragmentation is the hydrogen atom from position C5; however, it is not the only hydrogen atom that is eliminated. Contributions of hydrogen atoms from position $\mathrm{C} 4$ and from the phenyl ring in the loss of the $\mathrm{OH}$ group were excluded based on the results obtained for cis-5 and cis-7.

Notably, in the mass spectra of the cis-1 isomer and all of their selected deuterium labeled analogues, a peak at $\mathrm{m} / \mathrm{z} 171$ is present. Accurate mass measurements confirmed the elemental composition of this ion and allowed us to assume that it corresponds to a protonated form of a diethyl 


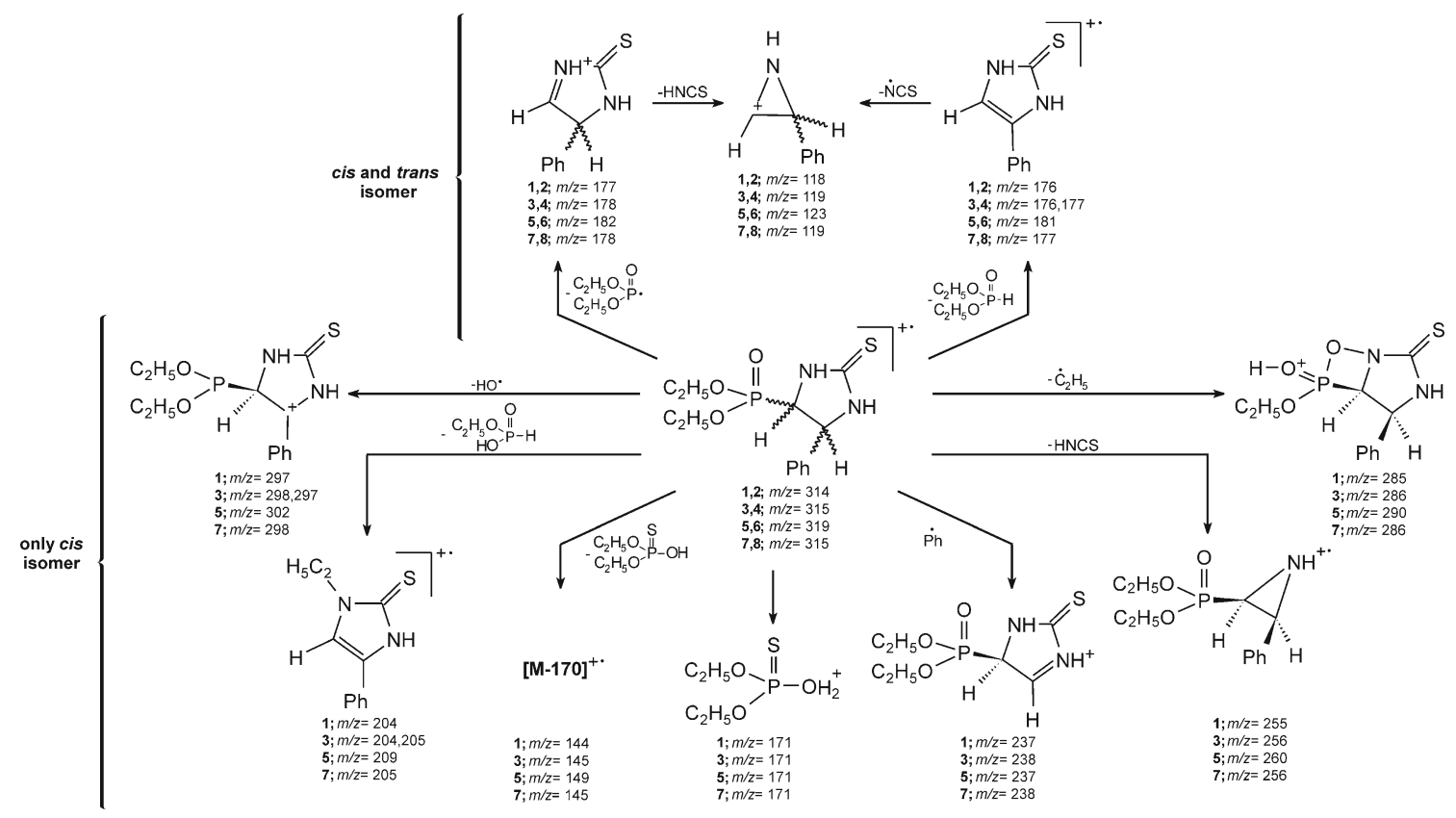

Scheme 4. Fragmentation patterns of the studied compounds

thiophosphonate molecule. The presence of this ion in the mass spectra of all of the cis isomers suggests that, during the process of fragmentation, hydrogen atoms from both N1 and N3 participate. A shift of one and two $m / z$ units of this peak was observed only for the $N$-deuterated $c i s-\mathbf{1}$ isomer. The same observation was noted in the case of elimination of the diethyl thiophosphonate molecule, which was also observed for all of the cis isomers.

Interestingly, the two previously discussed processes of fragmentation did not involve the hydrogen atom from the C5 carbon, which was eliminated in the diethyl phosphite molecule. This result may suggest that a different mechanism governs the elimination of diethyl thiophosphonate compared to the elimination of DEPI.

\section{Conclusions}

The computational study reported here provides a reasonable picture of the fragmentation pathways, including the energetics and ion structures for diastereoisomers of protected 1,2-diaminoalkylphosphonic acids. For the trans isomer, the leading fragmentation pathway is the elimination of $(\mathrm{EtO})_{2} \mathrm{POH}_{\mathbf{c}}$ (highest $\mathrm{TS} 1=17.1 \mathrm{kcal} / \mathrm{mol}$ ). Other reactions, such as the loss of $(\mathrm{EtO})_{2} \mathrm{PO}^{*}$ (highest $\mathrm{TS}=25.4 \mathrm{kcal} /$ $\mathrm{mol}$ ) or $(\mathrm{EtO})_{2} \mathrm{POH}_{\mathrm{a}}$ (highest TS2 $=36.2 \mathrm{kcal} / \mathrm{mol}$ ) make their own contributions in the fragmentation of the trans isomer. In case of the cis isomer, the leading reaction pathway is the loss of $(\mathrm{EtO})_{2} \mathrm{PO} *$ (highest $\mathrm{TS}=20.8 \mathrm{kcal} /$ mol). Other fragmentations that are likely to occur are the eliminations of $(\mathrm{EtO})_{2} \mathrm{POH}_{\mathbf{a}}$ (highest $\mathrm{TS} 2=30.4 \mathrm{kcal} / \mathrm{mol}$ ) and $(\mathrm{EtO})_{2} \mathrm{POH}_{\mathbf{c}}$.

In our opinion, the presented study has shown that the results from mass spectrometry and a theoretical approach to fragmentation of diastereoisomeric compounds are in good agreement. Such an approach can open a pathway to make comparative predictions for the fragmentation of new diastereomeric species and to assign a relative configuration in cases where only one diastereoisomer is under investigation.

\section{Acknowledgments}

The authors thank Professor Marek Potrzebowski for his invaluable editing suggestions.

\section{Open Access}

This article is distributed under the terms of the Creative Commons Attribution License which permits any use, distribution, and reproduction in any medium, provided the original author(s) and the source are credited.

\section{References}

1. Mandelbaum, A.: Stereochemical effects in mass spectrometry. Mass Spectrom. Rev. 2, 223-284 (1983)

2. Splitter, J.S., Turecek, F., Eds.: Applications of Mass Spectrometry to Organic Stereochemistry. VCH: New York, p. 265-289 (1994)

3. Giannousis, P.P., Bartlett, P.A.: Phosphorus amino-acid-analogs as inhibitors of leucine aminopeptidase. J. Med. Chem. 30, 1603-1609 (1987)

4. Tao, M., Bihovsky, R., Wells, G.J., Mallamo, J.P.: Novel peptidyl phosphorus derivatives as inhibitors of human calpain I. J. Med. Chem. 41, 3912-3916 (1998)

5. Orsini, F., Sello, G., Sisti, M.: Aminophosphonic acids and derivatives. Synthesis and biological applications. Curr. Med. Chem. 17, 264-289 (2010)

6. Mucha, A., Kafarski, P., Berlicki, L.: Remarkable Potential of the alphaaminophosphonate/phosphinate structural motif in medicinal chemistry. J. Med. Chem. 54, 5955-5980 (2011)

7. Lejczak, B., Kafarski, P.: Biological activity of aminophosphonic acids and their short peptides top. Heterocycl. Chem. 20, 31-63 (2009) 
8. Lejczak, B., Kafarski, P., Zygmunt, J.: Inhibition of aminopeptidases by aminophosphonates. Biochemistry 28, 3549-3555 (1989)

9. Drabik, E., Błaszczyk, R., Gajda, T., Sochacki, M.: Stereochemical effects in fragmentation of diastereoisomers of protected diethyl 1,2diamino-alkylphosphonates. Rapid Commun. Mass Spectrom. 24, 2324-2328 (2010)

10. Shendage, D.M., Frohlich, R., Haufe, G.: Highly efficient stereoconservative amidation and deamidation of $\alpha$-amino acids. Org. Lett. 6, 3675-3678 (2004)

11. Błaszczyk, R., Gajda, T.: Direct synthesis of protected diethyl 1,2diaminoalkylphosphonates. Tetrahedron Lett. 48, 5859-5863 (2007)

12. Frisch, M.J., Trucks, G.W., Schlegel, H.B., Robb, M.A., Cheeseman, J.R., Montgomery, J.A. Jr., Vreven, T., Kudin, K.N., Burant, J.C., Millam, J.M., Iyengar, S.S., Tomasi, J., Barone, V., Mennucci, B., Cossi, M., Scalmani, G., Rega, N., Petersson, G.A., Petersson, G.A., Nakatsuji, H., Hada, M., Ehara, M., Toyota, K., Fukuda, R., Hasegawa, J., Ishida, M., Nakajima, T., Honda, Y., Kitao, O., Nakai, H., Klene, M., Li, X., Knox, J.E., Hratchian, H.P., Cross, J.B., Bakken, V., Adamo, C., Jaramillo, J., Gomperts, R., Stratmann, R.E., Yazyev, O., Austin, A.J., Cammi, R., Pomeli, C., Ochterski, J.W., Ayala, P.Y., Morokuma, K., Voth, G.A., Salvador, P., Dannenberg, J.J., Zakrzewski, V.G., Dapprich, S., Daniels, A.D., Strain, M.C., Farkas, O., Malick, D.K., Rabuck, A.D., Raghavachari, K., Foresman, J. B., Ortiz, J.V., Cui, Q., Baboul, A.G., Clifford, S., Cioslowski, J., Stefanov, B.B., Liu, G., Liashenko, A., Piskorz, P., Komaromi, I., Martin, R.L., Fox, D.J., Keith, T., Al-Laham, M.A., Peng, C.Y., Nanayakkara, A., Challacombe, M., Gill, P.M.W., Johnson, B., Chen, W., Wong, M.W., Gonzalez, C., Pople, J.A.: Gaussian 03 Revision C.02. Gaussian, Inc.: Wallingford, CT
13. Becke, A.D.: Density-functional thermochemistry. 3. The role of exact exchange. J. Chem. Phys. 98, 5648-5652 (1993)

14. Lee, C.T., Yang, W.T., Parr, R.G.: Development of the Colle-Salvetti correlation-energy formula into a functional of the electron-density. Phys. Rev. B 37, 785-789 (1988)

15. Hehre, W.J., Radom, L.: Ab initio molecular orbital theory. Wiley, New York (1986)

16. Foresmann, J.B., Frisch, Æ.: Exploring chemistry with electronic structure methods, 2nd ed. Gaussian Inc.; Pittsburgh, PA, (1996)

17. Zhao, Y., Truhlar, D.G.: The M06 Suite of density functionals for main group thermochemistry, thermochemical kinetics, noncovalent interactions, excited states, and transition elements: two new functionals and systematic testing of four M06-class functionals and 12 other functionals. Theor. Chem. Acc. 120, 215-241 (2008)

18. Glendening, E.D., Reed, A.E., Carpenter, J.E., Weinhold, F.: NBO ver. 3.1.

19. Dennington, R., Keith, T., Millam, J.: GaussView ver. 4.1, Semichem Inc.: Shawnee Mission KS, (2009)

20. Kanawati, B., Joniec, S., Winterhalter, R., Moortgat, G.K.: Mass spectrometric characterization of 4-oxopentanoic acid and gas-phase ion fragmentation mechanisms studied using a triple quadrupole and time-of-flight analyzer hybrid system and density functional theory. Rapid Commun. Mass Spectrom. 22, 2269-2279 (2008)

21. Kanawati, B., von Saint-Paul, V., Herrmann, C., Schäffner, A.R., Schmitt-Kopplin, P.: Mass spectrometric stereoisomeric differentiation between $\alpha$ - and $\beta$-ascorbic acid 2-O-glucosides. Experimental and density functional theory study. Rapid Commun. Mass Spectrom. 25, 806-814 (2011) 